\title{
EDUCATING FOR RESEARCH
}

Taka Oguisso*

Nursing research has been widely studied and discussed by nurse educators over the last two decades, as it is potentially a major contributor to improving peoples's health and welfare. Yet, the development of this essential research has been slow in many countries, primarily due to lack of human resources.

Convincend that nurses play a vital role in the health care system, the International Council of Nurses (ICN) is continually working to influence national and international health policies at both levels, and to put nursing on an equal footing with other professions.

One ICN's priority over the past five years has been "to work with national nurses" associations to encourage and facilitate the development of research in nursing and by nurses and the dissemination of research findings. And the priority of facilitating and enhancing nursing research was reaffirmed by the Council of National Representatives (CNR) in 1991.

Over the past two years ICN has carried out two activities within this priority field. The first was to revise and publish the second edition of the "Directory of Nursing Research Centers". The second was organizing with the National Center for Nursing Research (NCNR) at the National Institutes of Health (USA), a Task Force on International Nursing Research, which met in 1990.

The Task Force focused on two areas: one the necessity to develop scientific knowledge to undergird nursing practice, and two, the need to bridge the gap between practice and research by channelling research findings to the practice settings.

The Task Force participants, who represented nine countries, including Brazil, reported varying levels of progress and sophistication in nursing research, and confirmed the uneveness that exists in the evolution of the nursing research internationally. They noted that in some countries nurses are not involved in any form of nursing research, while in others research is in its beginning stage. There are, of course, countries where nursing research is well established, respected and reasonably funded. The Task Force thus recommended that ICN become the international focal point for facilitating nursing research within the profession, particularly in the neediest countries.

- Enfermeira. Professor Titular do Departamento de Orientação Profissional da Escola de Enfermagem da USP. Nurse Consultant of the International Council of Nurses 
One ICN function, as a federation of national nurses associations and the "authoritative voice for nurses and nursing internationally" is to assist them in promoting and improving nursing research. To date, ICN has chosen not to actually carry out nursing research on its own and has not established research priorities for nursing internationaly. ICN works with member associations through giving guidelines and professional assistance in some of their needs, including in research.

In implementing its function to promote nursing research, ICN takes into consideration the following factors:

- The specific social and cultural concerns of member associations;

- The health needs and resources available in the country;

- The universal aging trend of the population;

- The progressive utilization of technology in nursing care and reporting; care; and,

- The increasing awareness of cost-effectiveness components of health

- ICN's present and ongoing priorities, such as expanding empowerment of nurses and nursing efforts, socio-economic welfare, nursing management, AIDS, mental health, ethical issues, leadership development and increasing policy effectiveness nursing costs and benefits, classification of nursing practice and facilitation and enhacement of nursing research.

Merging the ICN perspective and trends in health care systems, the following are likely to become the focus for ICN's work in the nursing research field: nurses;

- Promote and facilitate the development of research in nursing and by

- Foster the dissemination of research findings and its utilization in nursing practice;

- Encourage communication, collaboration and networking in research within and across countries;

- Facilitate crosscultural research; journals;

- Encourage publication of more national and international research

- Promote meetings of nurses researchers;

- Assist national nurses' associations to establish ethical research standards;

- Stimulate national nurses' association to support nursing research initiatives; to set mechanisms for planning nursing research development as well as career structures for nurse researchers; and to formulate a national nursing research agenda;

- Propose and support the participation of nurses in research committees and in all activities related to health policy making, planning and resource development at international or national levels; and

- Cooperate with other groups involved in nursing research.

Therefore ICN is urging its_member associations to ensure that nurses have access to professional career structures that provide for advancement and remuneration for demonstrated competence, experience and educational preparation in different roles, at different levels within and across all field of 
nursing. The research role must be given its proper place within the career choices available to nurses.

\section{Nursing research worldwide}

Nursing as well as nursing research must now be viewed in the context of the rapid and radical changes occurring throughout the world.

Significant activity is taking place in European countries. In line with the objective of enabling free mobility of people and services within the twelve members of the European Community (EC), directives have been passed by the EC legislature which set minimum standards for the formal qualification of nurses responsible for general care. These directives stipulate that member states must meet certain criteria in their educational programmes. Through this mechanism the EC countries have achieved the mutual recognition of the formal qualification of a nurse.

Stallknecht stated that the main fear among nurse leaders had been that the minimum standards would prevent the more advanced countries from developing better educational programmes, especially advanced nursing education where much of the preparation for the research role takes place. In practice this has not proved so, and in most EC countries educational programmes have continued to evolve and improve.

A Standing Committee of Nurses of the EC was created in 1971. It consists of representatives from national nurses associations in membership with ICN from each of the EC member states. The Committee is autonomous and independent but maintains close links with ICN and the Nordic Nurses Federation, and is recognised by the Commission of the EC as the official liaison committee for nurses.

One of the objectives of the Standing Committee is " to be instrumental in bringing about and furthering the cooperation between international health organizations, research institutions and the EC". It also believes that "nursing research provides knowledge and understanding of factors for the promotion of health and prevention of illness and the improvement of nursing practice".

The European Office of the World Health Organization (WHO) has been very influential and encouraged nurses to take an active role in health planning and promotion. At the WHO European Conference on Nursing, in Viena (1988), a Declaration on Nursing was adopted by the representatives from all European countries. The role of the nurse was defined as one based on a generalist training with emphasis in primary health care and with the possibility of further education in several clinical specialities, management, education, and research. The participants of the Conference also recommended that innovative nursing services should be developed so that there is a focus on health rather than on disease and that nursing research be part of all fields of nursing practice, education and leadership.

All over Europe, nurses are working on the development of nursing standards and the registration of nursing data. This trend is further advanced in North America, but the systems developed there are closely related to the private health care system - and that is not what European nurses want, according to Stallknecht. 
Another European development has been the creation in 1978 of the Workgroup of European Nurse Researchers (WENR). This is made up of European nurses nominated by national nurses associations from 20 countries (including Eastern Europe). They meet yearly to present annual reports on research activities and discuss issues related to nursing research.

Every other year an open conference is organized, and this provides opportunities for nurse-researchers outside this group to share experiencs and results. These meetings and conferences have brought about a rapid development of research interest among European nurses.

Nurses in all Eastern or Central European countries such as Poland, Hungary, Czechoslovakia, Croatia, Slovenia, etc as well as the Baltic countries are intensively involved in the process of changes.

Language is a very serious problem in Europe: in the EC there are 12 countries and 9 official languages. Therefore, publicising and holding meetings are very difficult and expensive. Also access to updated information is sometimes very limited.

In countries of the South East Asia and Western Pacific regions - such as Japan, Korea, New Zealand, Australia, Thailand, India, Phillippines, ctc nursing research is being carried out, primarily within the universities and schools of nursing by faculty members and students. In many of these countries the nursing organizations and schools of nursing have been instrumental in laying the roots for nursing research in their countries. In these regions, nurses associations utilise conferences and other more informal meetings to disseminate research findings. In such gatherings researchers share their experiences in their language with other colleagues and general nurses.

In the Eastern Mediterranean and African countries nursing research is not yet a first priority. This is not due to a lack of awareness of the importance of research. Nurses are still fully involved in reorganising and developing basic nursing services and education. Although sparsely distributed, nurse-researchers do exist in Africa and the ground for nursing research is particularly fertile.

In Latin America, virtually all countries have established bachelor degree programmes for nurses, and many countries have one or more master programmes on nursing implemented, where faculty and students do research. Brazil, as we know, has alrecidy 5 programmes at doctoral level studies, and was the first and only country with specific programme at this level for nurses. Puerto Rico is presently implementing its first doctoral studies for nurses.

In December, 1991, WHO sponsored an Inter-regional Workshop on Nursing Research in Primary Health Care, with nurse-researchers representing 18 countries fiom all six regions, held in New Delhi. The workshop was designed to facilitate the development of research ideas and the conduct of research projects that would improve the health of people in the communities, countries and regions represented.

The workshop participants recommended to the WHO member states: to promote the education and development of nurse researchers in order to develop cost-effective ways of addressing priorities and developing health care needs; and to promote participation of nurses and midwives in health research advisory committees at national level. 


\section{Research and nursing education}

Reilly reports that the first research study by a nurse was tha 1906 survey by Adelaide Nutting on the educational status of nursing, published by the US Commission on Education. In 1912 a subsequent study by another nurse presented comparative data on statutory requirements of different states in the USA. In the mid-1920s survey studies about nursing and nursing education were developed. The findings relative to the educational practices in nursing education were appalling, since they were so far out of the mainstream of educational preparation for other professionals. The author queries why the early studies in nursing address educational issues rather than practice concerns. Research and the university there, in the USA, as well as in Brazil are complementary notions.

The American Journal of Nursing issue of June 1940 carried one of the first articles on research methodology by Bookseller. Most of the research done by nurses at that time was done by graduate students, and, as we can expect, most were in the field of nursing education. The publication of the journal "Nursing Research ", started in 1952, marked historically a standpoint in this field.

This historical evolution of the nursing research in the USA sounds very familiar to all of us, Brazilian and Latin American nurses. Particularly in Brazil we have followed similar paths and patterns for the development of nursing research and the nursing profession.

To foster excellence in nursing and promote the development of a substantiated body of knowledge, nurse researchers, educators and practitioners need to identify the nursing research priorities for the country, which should be revised on a continual basis. These priorities will facilitate the selection of scientific opportunities and initiatives, the promotion of depth in developing a knowledge base for nursing and direction for nursing research within the discipline.

The participants of the ICN Task Force on International Nursing Research - referred above - has set the following priorities:

- Recognise nursing research as an integral aspect of nursing practice: and education in and across all countries; standards;

- Encourage all national nurses associations to establish ethical research

- Assure preparation of nurse researchers for positions on the faculty of: masters and doctoral programmes and for positions in clinical research;

- Promote depth in the knowledge base for nursing practice; and,

- Facilitate crosscultural research.

For each priority the group defined the strategies for the ICN and for national nurses associations.

The focus on nursing education has been always present in all ICN activities throughout the ages and resulted in the creation of the Florence Nightingale Foundation, in 1912, to provide educational opportunities to nurses. In 1933, it was decided to include nursing research in its comprehensive educational programme.

The first ICN Congress, held in 1901 (USA) as well as others organized in the 1910 and 1920 s decades were more an international forum for presentation of reports on the status of nursing in different countries, educational standards, 
minimum curriculum requirements, hospital management, tuberculosis, maternity care, etc. Only in 1930s, nurses started to present and publish research findings at ICN meetings.

If we were requested to set a Brazilian Nursing Research Agenda we would likely include the following priorities: primary health care, health promotion and development, maternal and child care, appropriate technology and care, nursing case management, leadership and some other clinical specialties.

The WHO in the 1989 Resolution on Strengthening Nursing and Midwifery in Support of Strategies for Health for All was asked "to promote and support the training of nurse/midwifery personnel in research methodology in order to facilitate their participation in health research programmes, including the development of information systems on nursing and midwifery".

Again, in 1992, WHO concerned at the continued shortage of nursing and midwifery personnel and the urgent need to recruit, retain, educate, and motivate sufficient numbers to meet present and future community health needs; and, recognising the need to increase the WHO's nursing and midwifery activities at all levels, urged Member States (WHA 45.5) to: 1)... "2) strengthen managerial and leadership capabilities and reinforce the positions of nursing and midwifery personnel in all health care settings and at all levels of service, including the central and local services of health ministries and the local authorities for the programmes concerned; 3) enact legislation, where necessary, or take appropriate measures to ensure good nursing and midwifery services; 4) strengthen education in nursing and midwifery, adapt educational programmes to the strategy for health for all, and revise them where appropriate, in order to meet the changing health care needs of populations; 5) promote and support health services research that will ensure the optimal contribution of nursing and midwifery to health care delivery, with particular emphasis on primary health care".

\section{Conclusions}

There is a commom theme that permeates many nursing research reports and documents from all over the world: the low or lack of resources available for nurses. Even where funds exist, they are small compared to the resources allocated to other professionals, particularly to biomedical researchers. Hopefully the shift in health research promoted by WHO may influence governments to invest more on health than on illness. Hopefully, too, more thought will be given to creating an environment that motivates and rewards young scientists, including nurses. The WHO initiative to convene the inter-regional workshop, referred earlier is an example.

Therefore, it is time for more concrete actions. As action requires knowledge, research is the best way to improve the quality of nursing care, the use of advanced technologies and, consequentely, to create new knowledge. Thus, nursing research should be vigorously fostered rather than discussed as an academic exercise. Through concerted actions, nurses can make a difference in health care.

We must be more proactive, proposing ideas on nursing research to higher authorities and suggesting alternative to improve the health care of the people. 
One example is on cost factors. They are of great interest to managers and nursing research can develop many cost savings anf cost effective changes in patient care.

Being as international federation of 106 member associations with a variety of development stages, ICN sees its role as that of facilitating the network: and the communication among nurse-researchers, disseminating nursing research findings, and stimulating research utilization in the practice through mechanisms available to it such as its official journal (The International Nursing Review), special meetings during the ICN quadrennial congresses, and speaking for nursing research in international fora.

\section{BIBLIOGRAFIA}

EUROPEAN COMMUNITY. Standing Committee of Nurses of the EC. Policy statement. Brussels, 1992.

INTERNATIONAL COUNCIL OF NURSES. Blueprint for ICN programme 1988-1993 toward more effective participation in health policy making and health care delivery. Geneve, 1987.

INTERNATIONAL COUNCIL OF NURSING. Future direction report of the board of directors/staff workshop, 17-18, October, 1990. Geneva, 1991.

REILLY, D. E. Research in nursing education. Nurs. Health Care, v.11, n.3, p.139-43, 1990.

STALLKNECHT, K. Nursing in Europe. Brit. Med. J., v.304, n. 6826, p. 561-2, 1992.

TASK FORCE ON INTERNATIONAL NURSING RESEARCH, Geneve, 1990. Nursing research worlwide: current dimensions and future directions. Geneve, International Center for Nursing Research/International Council of Nurses, 1990.

WORKGROUP OF EUROPEAN NURSE RESEARCHERS - WER, 14, Copenhagem, Sept. 1991.

WORLD HEALTH ORGANIZATION. Summary report of the European Conference on Nursing, Vienna, 21-24 June 1988. (EUR/ICP/HSR 329 (S), 694N). (WHA 45.5).

Strengthening nursing and midwifery in support of strategies for health for all. Geneva, 1992.

International Workshop on Nursing Research in Primary Health Care, New Delhi, 9-13 December 1991. Geneva, 1992. (HRH/NUR/92). 